\title{
Poverty and Sickness: The High Costs of Ill-Health
}

Jane Corbett

\section{Introduction}

Differences in physical vulnerability to sickness affect the welfare both of the individuals concerned and of the households to which they belong. The vulnerability of households to having sick members varies, as does their capacity to cope with sickness and its economic consequences. While the physical vulnerability of different social and age groups to sickness has been the subject of considerable research, the economic consequences for the long-term viability of households have been relatively neglected.

Members of poor households tend to be especially vulnerable to ill health. Not only is undernutrition more common in poor households, but they are more likely to be living in environmental conditions which bring high risks of infectious and vector-borne diseases. Socially and economically, they are vulnerable because of the difficulties they experience gaining access to and paying for treatment. Physical, social and economic factors combine to make sickness potentially more frequent, harder to deal with, and a more serious economic liability in poorer households.

The economic vulnerability of poorer households to ill health has important policy implications. Economic recession and the adoption of 'structural adjustment' policies have put severe pressure on health budgets in many countries. In some, this has led to cuts in health expenditure with the disintegration of rural health services [Abel-Smith 1986; Cornia, Jolly and Stewart 1987]. Introducing or increasing user charges for curative health is part of the current policy debate. Whatever the rationale and intentions, budget cuts and user charges could both reduce the protection offered to the poor against ill health, and at the same time increase the costs they face in dealing with it. Consequently, the need has been recognised for special measures to protect the poor [World Bank 1987]. To be effective, these need to be based upon an understanding of household vulnerability and the economic costs of coping with sickness.

\section{Sickness, Coping Strategies and Vulnerability}

Sickness can have important economic consequences in a number of ways, the most immediate being increased expenditure incurred in seeking treatment.
If the individual who falls sick is economically active, sickness can result in the loss of current income, or even the loss of employment. Even where sick individuals are not economically active, if other family members have to devote time to care for them, this can also lead to loss of income. If the sickness of an active adult becomes chronic or leads to disablement or death, this adversely affects the dependency ratio of the household.

Any acute or prolonged episode of sickness can therefore result in the need to finance additional expenditure, to replace lost income and to reallocate work and domestic responsibilities. Expenditure decisions relating to medical care can be fraught with uncertainty in a number of ways. Uncertainty about the nature, causation and possible duration of the illness, about the most effective forms of treatment, about the availability of different kinds of treatment, about the costs likely to be incurred, and outcome if no treatment is sought, may all be compounded by the need to take decisions rapidly if the person's condition seems likely to deteriorate. In addition the distress and suffering caused by ill-health to the sick and to those close to them also mean that deciding how to cope with episodes of sickness can be complex and demanding, making them far from a simple matter of economic calculus.

Entitlement to sick pay or other forms of income support and health insurance or subsidised health care can all considerably reduce the costs that are borne by the individual or household. But in the absence, or only partial provision, of such measures, some if not all of the costs fall upon the household concerned.

An important set of hypotheses about the economic consequences of sickness at a household level has been developed by Chambers (1983) in the context of a more general discussion about the nature of poverty and processes of impoverishment. He argues that sickness can be one of several important factors which lead to the further impoverishment of already resource-poor households.

Chambers argues that households are subject to a range of contingencies which may lead to the loss of current income and/or necessitate heavy expenditure. These contingencies are grouped into five broad categories; social conventions, disasters, physical incapacity (including sickness), unproductive 
expenditure and exploitation. It is suggested that households vary in the extent to which they have been able to develop 'buffers' such as rescrves of cash, which will enable them to cope with these contingencies without adverse economic consequences for the houschold. Households which lack these buffers have little choice but to cope by the sale or mortgaging of vital assets which will prejudice the future cconomic position of the houschold. Vulntrability therefore reflects the lack of buffers to cope with contingencies such as sickness.

Chambers goes on to argue that a contingency such as sickness can "often force poverty ratchets, entailing the irreversible loss or sale of assets, making pcoplc poorer or more vulnerable to becoming poorer still'. Sickness is seen as the kind of contingency which can lead to a process of impoverishment which it is difficult to reverse, and it is suggested that 'a prolonged illness can impoverish utterly' [Chambers 19837 .

An additional hypothesis developed by Chambers is that the incidence of these sickness related poverty ratchets may be increasing [Chambers 1983, 1987] because allopathic health care is becoming more widely available in developing countries, particularly in rural areas. Such care, it is argued is often only available at great expense to the user and payment terms may be stringent compared to other types of treatment, with neither credit nor payment in kind accepted. Chambers predicts a high and rising incidence of asset disposal and indebtedness as a consequence, and argues that health expenditure may be an increasingly important cause of impoverishment.

\section{Empirical Evidence on Sickness and Poverty Ratchets}

To explore these questions, empirical evidence is required to examine the association between sickness and economic changes which are difficult to reverse. Relevant evidence would include significant drops in current income, distress sales of assets which are not subsequently recovered, the accumulation of consumption loans and other kinds of indebtedness, and increased dependency ratios. Evidence on how sensitive the poor are to increased costs of allopathic health care would also be useful, though such studies are rare.

Just how high the costs of sickness can be is shown by a study carried out in an urban slum in Bangladesh [Pryer in this Bulletin]. With most households dependent on casual labour for much of their income, 24 per cent of households reported labour days lost in the previous month due to sickness, and for the poorest income quartile this led to an average loss of monthly income of 74 per cent in affected households. Levels of household medical expenditure can also be very high; a study in the Ivory Coast found that average household medical expenses were higher than the monthly minimum wage, and even amongst the poorest houscholds as much as 10 per cent of income was used for this purpose [Lasker 1981]. A recent study in Thailand found that 60 per cent of 'involuntary' land sales were duc to high medical bills [Abcl-Smith 1986]). In an area where there is littlo access to medical carc, Evans' study of the impact of river blindness provides a detailed illustration of the conscquences of this illness on the work capacity of adults, the area they werc able to farm, their ability to generate off-farm sources of income and the subsequent impact on the nutritional status, health and life expectancy of other family members [Evans in this Bulletin].

Several studies provide evidence that the economic consequences of sickness can be severe cnough to impoverish those concerned through a ratchet effect. A study in Gujarat and Rajasthan examined the financial problems incurred by families in coping with the morbidity and mortality experienced during epidemics [Dogra 1988]. In an area with only rudimentarygovernment medical care, many families were forced to resort to private medical care, and financed this through a combination of taking out loans at high interest, mortgaging or selling animals, and pledging future crops. Both the economic and health status of these families had already been weakened by three years of consecutive drought, making them both physically more susceptible to sickness from malnutrition and unable to finance medical treatment without endangering the economic viability of the household.

Further more detailed evidence is provided by the two studies by Evans and Pryer already mentioned. Although carried out in very different contexts (in terms of the main income sources of the households concerned, their relative access to medical care, access to credit and support from other households and the different kinds of health problems to which they were subject) both studies trace a deterioration amongst households in their ability to generate income and in their dependency ratios. Both also demonstrate that the impact of the sickness of adults who were previously economically active on the health, nutrition and even life expectancy of other family members, may be severe.

In Pryer's study, households which are dependent on casual labour or self employment, which lack any form of employment protection, have few savings or any kind of health insurance, with adults incapacited by sickness, accumulate large consumption loans to finance lost income and tend to finance the costs of medical treatment through the sale of assets. This study also illustrates how the combined effects of impoverishment and ill-health can be transmitted from one generation to another. 
In Evans' study of the impact of river blindness in Guinea, the combination of the progressive nature of this disease and the absence of accessible medical care means that the ability of these households to farm or generate off-farm sources of income, declines over time until virtual destitution results. It is worth noting that in both these cases it is the chronic sickness of adults which leads to impoverishment, as a result of changes in the household dependency ratio.

Pryer's study is one of the few to provide evidence on which kinds of costs are most crippling economically to a household as a result of sickness. Although this will depend on the kind of livelihood followed and access to medical care, in the Bangladesh case the income lost from reduced earnings was always more than double, and sometimes over ten times, the extra costs of medical treatment. With the major source of income being either casual labour or self-employment, unless the labour of other members can be substituted, it may be very difficult to constrain the income lost due to sickness. By contrast, the financing of medical treatment was directly linked to the availability of assets to be sold and once exhausted, expenditure on medical treatment ceased. There may be some discretion, therefore, over the extent to which impoverishing expenditure for medical treatment is undertaken, but little over lost income.

There is also good evidence to demonstrate how physical and economic vulnerability interact. In Pryer's study those households where adults were incapacitated by illness had a threefold higher risk of having malnourished children as those without, and this study also traced the increase in malnutrition and morbidity in both women and children as their families became more deeply impoverished. Dogra's study of the Indian epidemics demonstrates how fatal epidemics took place amongst a population already weakened by drought, resulting in a lack of savings or other assets which could have been used to finance medical care without prejudicing the income generating capacity of the household, and where malnutrition had already increased physical susceptibility to disease.

\section{Evaluation of the Poverty Ratchets Model}

The poverty ratchets model suggests that sickness impoverishes already poor households, which are plunged into a progressive spiral of declining health and economic status.

However, there are other ways in which the links between sickness and impoverishment need further examination. Inherent in the poverty ratchets model is the assumption that poor households have only one form of response to sickness. The only kind of coping strategy we might expect to observe is the accumulation of buffers - where possible - and resort to impoverishing actions, such as the sale of assets and increased indebtedness, where these are lacking.

One way of coping with sickness is simply not to seek treatment where this might jeopardise the economic viability of the household. Poor households faced with family sickness and with access to medical care do not always use it. Chen's study in Bangladesh found that households living near a diarrhoea treatment centre did not always seek treatment for sick children, particularly little girls [Chen et al. 1981]. In Pryer's study, despite the presence of a free nutritional rehabilitation centre, malnourished children were either withdrawn early or not taken to the clinic because adults could not spare the time for this purpose [Pryer, this Bulletin]. In rural Ivory Coast, Dor et al. found that poor households were particularly likely to be deterred by the time costs of existing health facilities [Dor et al. 1987]. In Peru Gertler et al. (1987) found that low income households were much more likely to be deterred from the use of health facilities by increases in user charges.

Coping by not seeking treatment, even when it is relatively accessible, indicates a survival strategy which avoids indebtedness or destitution at the cost of greater risk to the health - or even survival - some household members. Where this is the case, the poverty ratchets model is over-simplified, and a useful refinement would emphasise potential impoverishment through loss of income in addition to expenditure on medical treatment and the high costs of avoiding impoverishment by not seeking treatment.

One gain from better, cheaper and more accessible public health facilities is to reduce the acute dilemmas of poor. households faced with having to choose between on the one hand, little or no treatment, and on the other having to bear the costs of medical treatment and deeper poverty and destitution.

\section{Possible Strategies for Reducing Vulnerability to Sickness}

In practice there are several strategies which households may adopt to deal with their health problems. These include:

- invest ment in preventative health care to reduce the likelihood of sickness;

- insuring against possible future sickness (e.g. by insurance schemes, membership of mutual credit networks, the accumulation of non-essential assets;

- minimising costs to the household economy by taking immediate curative care when sickness strikes;

- not seeking treatment if it is likely to impoverish the household; 
- not taking either preventative or initial curative care, with the risk of incurring larger medical costs subsequently.

In contrast to Pryer's study, Ratnayake's work in Sri Lanka (1988) demonstrates that poor households appear to adopt quite different strategies from those observed in Bangladesh. In Sri Lanka, households invest heavily in preventative care in order to reduce the susceptibility of household members to sickness. Ratnayake found that households pract ise a range of preventative methods both to reduce the risks of sickness and to contain levels of sickness and undernutrition. Examples are immunisation, deworming, malarial spraying, and immediate treatment of diarrhoea. Such risk mininisation was not simply a luxury of the better off; these practices were observed even amongst quite poor households and indeed, they can be argued to be even more essential for those for whom their labour, itself dependent on health, is their main or only asset.

Sri Lanka's relatively high levels of public investment in education, in schemes to guarantee minimum food entitlements, and in public health and sanitation have probably all made it easier for even poor households to pursue this kind of risk minimising strategy successfully.

Several studies also suggest that even when households do not invest much in reducing the risk of sickness, once a household member falls sick they attempt to minimise the costs of this to the household [Igun 1979; Lasker 1981]. Ratnayake's study in Sri Lanka, for example, suggested that as soon as a child develops signs of a sickness such as diarrhoea, immediate remedial action is taken in the form of home treatment, and then if rapid recovery does not follow, the child is quickly taken to a medical centre. This is done to avoid loss of income incurred should the child become seriously ill.

This contrasts with the alternative strategy of delaying treatment unt il it has become evident that the sickness is likely to be very serious. This may result in large curative bills, for example through hospitalisation, when cheaper curative treatment may have been possible earlier [Gilson 1988]. Once a life threatening condition develops, then households may be willing to seek treatment no matter how high the total cost [Igun 1979], but this has the potential to be particularly impoverishing. While it may represent a form of cost minimisation in the short run, it incurs the risk of very large expenditures subsequently. It seems likely that this sort of strategy may be observed amongst households who do not have access to good information about treatment options for different sicknesses, who have little access to good quality cheap treat ment and who have slender or non-existent buffers or access to credit.

This sort of coping strategy is not really a strategy in the sense of choosing an optimal course of action, so much as a survival strategy, and is likely to be common amongst households for whom life represents a day to day struggle at the margin of economic survival. For these kinds of household, the possibility of sickness leading to further impoverishment may be very great.

Lastly, the strategy of not seeking treatment suggests the need to investigate vulnerability within the household and whether some kinds of individuals are more vulnerable than others. Analysis at the level of the household can neglect variation in the composition and behaviour of households, and conceal important relationships within them which lead to some individuals being at greater risk than others. This raises the question of whether sickness is treated indiscriminately within the household: might larger costs be incurred for some individuals than others? Are the economic consequences for the household of the health of different members taken into account when making expenditure decisions?

Evidence on this is not easy to find. Some of the strongest comes from Bangladesh, where there is also the strongest indication of bias in intra household food allocation [Chen et al. 1981; Pryer 1989], In the South Asian context boys can be expected to make a bigger long-term contribution to the household than girls, since girls may move to other households on marriage, and also command lower wages in labour markets.

\section{Implications for Research}

The greater vulnerability of poorer households to illhealth, the high costs of not being able to work, and their difficulty in paying for treatment, indicate the following priorities for research:

- the impact on health service utilisation, especially on the poor of introducing or increasing user charges;

- the relative importance in making households poorer of loss of income from ill-health, of changed dependency ratios, and of costs of medical treatment, including the effects of chronic ill health;

- the relative significance in impoverishment of different health problems (acute versus chronic, communicable versus degenerative, and endemic versus epidemic), particularly as disease patterns in many developing countries change;

- the impoverishing effects of adult ill health compared with child ill health;

- economic and power relationships within households and the relative vulnerability to health problems and access to treatment of different household members; 
- compirison of the impoverishing effects of death compared with recovery or the onset of at chronic condition.

\section{Policy Implications}

In discussing the kinds of ceonomic conscyuches which ill-health gives rise to. this article discussed at model of sickness latding to inpovtrishmunt through a ratchet effect. This ratiscs some very important policy issues about the expansion. costs and accessibility of government health facilitics. and about their potential role is a contributory fatuor in processis of impoverishmcnt.

Many policy makers are concerned with reducing poverty as well ats promoting efficicncy in the health sector. From the anti-poverty perspective cost recovery through incrcasing user charges may well be an inefficient usic of public resources. This will especially be so where it taks longer to improve preventative measures to reduce the physical vulnerability of the poor. than it takes to introduce charges for curative health care. Maintaining effective health services. free or at very low cost to poor users. even or especially in an era of recession and austerity. may have important distributional benefits and be a costeffective form of public spending since it can cost much more to reverse impoverishment than to prevent it. Quality of service also matters; where governmentfinanced healt h services are expanded. impoverishment from sickness will be little affected unless the services are better and more accessible to the poor than existing private treatment.

The health programme of many governments and international organisat ions of en concentrate resources on children because of their physical vulnerability to sickness. However, some of the evidence suggests that the ill-health or premature mortality of adults may matter as much, if not more. to the economic viability of the households to which they belong. When both economic and physical vulnerability are taken into account. the relative importance assigned to adult health problems may need to be reassessed.

Lastly, there are policy implications outside the health sector. Several studies suggest that the economic costs to households of income lost through sickness exceed those incurred in seeking treatment. This underlines the point that publicly organised health insurance schemes and other social security measures have great potential for reducing the impoverishing impact of ill-health.

\section{References}

Abel-Smith. B.. 1986. 'The World Economic Crisis: Pant 1: Repcrcussions On Health'. Ileallh Policy And Plamning vol 1 no 3. pp 202-13

Chambers. R. 1983. Rural Delalopment: Phaing the Last Iirst. longman

- 1987. personal communication to Commission on Health Rescatreb For Derelopment

Chon. L.. Huty. E. and D'Souza. S.. 1981. "Scx bias in the family allocation of beatlh care in Batoladesb". Population

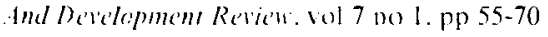

Corniti. G.. Jolly, R. and Stewart. F.. 1987. Adimstmon Wilh A Homan liaci. Clarendon Press. Oxford

Dogrit. B.. 1988. "The other epidemics'. Fonomics And

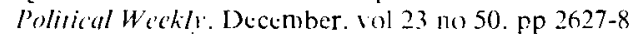

Dor. A.. Gertler. P. and Van Der Gaag. J.. 1987. 'Non pricc' rationing and the choice of medical care providers in rural Cotc Divoire. Iommal of Ileallh Economics. vol 6 no 4. pp 291-304

Evans. T.. 1989. 'The impact of personal disability on rurit houscholds: evidence from endemic atreas of river blindness in Guineat. IDS Bullotin vol 20 no 2. April

G.rtler. P.. Locaty. P. and Sanderson. W.. 1987. 'Are user fecs regressive? The welfare implications of health care financing proposals in Peru'. Jownal of Econometrics vol 36. pp 67-88

Gilson. L.. 1988. 'Government health care charges: is equity being abandoned?' Evaluation and Policy Centre Discussion Paper no 15. London School of Hygiene and Tropical Medicine

Igun. U:. 1979. 'Stages in health seeking behaviour: a descriptive model'. Social Science And Medicine vol 13A (4), pp 445-456

Lasker. J.. 1981. 'Choosing among therapies: illness behaviour in the Ivory Coast. Social Science And Medicine vol 15(a). pp 177-93

Pryer. J., 1989. 'When bread-winners fall ill: preliminary findings from a case study in Bangladesh. IDS Bulletin vol 20 no 2, April

Ratayake. N.. 1988. 'Hotsehold management strategies and vulnerability' paper prepared for IDS Workshop on Vulnerability and Coping. September

World Bank. 1987. Financing Healh Services In Developing Countries: An Agenda For Reform. World Bank. Washington D.C. 